\title{
VIRTUAL EVALUATION OF COMPLETE DENTURES SMILE ANATOMICAL RELATIONSHIPS
}

\author{
Mohamed Ahmed Alkhodary*
}

\begin{abstract}
Introduction: Esthetics is becoming more important to completely edentulous patients than ever before, and more of them are asking for the smile of movie stars. The purpose of this study was to adopt the Digital Smile Design (DSD) software as a new method for complete dentures smile evaluation, that is more reliable than the subjective judgement of the dentist, the patient, or the patients' relatives.
\end{abstract}

Material and Methods: Sixty patients, 22 females and 38 males, already having their dentures, ranging 40 to 70 years old agreed to participate in this study, where they were photographed in a smiling and a lip retracted position. The photographs were evaluated by one examiner who used a DSD software called Digital Smile System (DSS). Evaluation included coincidence of the dentures midline with that of the face, parallelism of the incisal maxillary plane to the inter pupillary line (IPL), and equality of the width of the maxillary 6 anterior teeth with the inter alar width (IAW) of the nose. Patients were also asked about their acceptance of the dentures teeth forms and color. Results of this study were statistically analyzed using the package for social science (SPSS version 20 for windows) where the data were displayed in the form of frequencies and percentages, and comparisons between the study groups were carried out using Chi Square test at significance level $\mathrm{p}<0.05$.

Results: The midline of the maxillary dentures was coincident with the midline of the face in 48 patients, and had a statistically significant relationship with the maxillary incisal plane ( $\mathrm{p} \leq .001)$, which was parallel to the IPL in 41 patients, whether it followed the lower lip line or not. These centrally aligned midline of the dentures also had a significant relationship with the combined width of the maxillary incisors and canines $(\mathrm{p}=.001)$ when it was equal to the IAW in 50 of the patients. Teeth forms were accepted by 47 patients with no gender significant difference $(p=.879)$, and 42 patients preferred a whiter shade with a significant difference for the females $(\mathrm{p} \leq .035)$.

Conclusions: The midline of the face and width of the nose helped correct selection of the width of maxillary incisors, and the inter pupillary line helped to properly orient their plane. Patients opinion regarding their teeth form and color must be taken into consideration carefully. The DSD software presented a simple and a reliable method to evaluate and create the complete denture smile. Complete denture smile conforms to the principles of DSD as it originated from the same biometric references.

KEY WORDS: Digital Smile Design (DSD), Complete Dentures Smile.

\footnotetext{
* Associate Professor, Department of Removable Prosthodontics, Faculty of Dentistry, Alexandria University, Egypt.
} 


\section{INTRODUCTION}

The teeth and their supporting bases are responsible for maintaining a pleasant and a normal facial expression for they hold the lips and facial musculature in proper physiologic position. Special attention to the clinical and laboratory procedures of complete denture construction can help maintain an esthetic smile even after loss of teeth. ${ }^{1-5}$

The dentogenic concept proposed by Frush and Fischer ${ }^{6-11}$ represents one of the earliest trials to produce esthetic dentures, it depended on the patients age, gender, and personality. Other studies have demonstrated the importance of artificial teeth positioning, and that the selection of their form and color, and symmetrically arrangement around the midline of the face, can affect the esthetic results. ${ }^{12-14}$

However, even if the artificial teeth were set to the approximate positions of their natural predecessors, there is a gradual reduction in the amount of maxillary incisors display and a gradual increase in the mandibular teeth exposure. ${ }^{15-22}$

The width of the nose from the outer border of one ala to the other presented a reference for selection of the width of the maxillary denture anterior teeth, and represented an easier and reproducible method compared to other methods using the golden rule and inter pupillary distance hypotheses. ${ }^{23-29}$

Studies concerned with the tooth forms have found that in any given race, several facial patterns can exist, accordingly, it was generally recommended to relate the tooth form the patients' personality, as dictated by the Dentogenic concept. Gender may however affect selection of the tooth form, being more rounded and ovoid for females, and more angular or square for males. ${ }^{30-32}$

Occlusal plane orientation in the mandibular arch is functionally related to the retro molar pad, commissures of the mouth, and the lateral border of the tongue. The maxillary posterior occlusal plane is usually made parallel to the ala-tragus line, while the anterior maxillary incisal plane is made parallel to the inter pupillary line (IPL) horizontally, and its vertical position is determined by lip relationships at rest and when smiling, and is better determined by the dentist from front centered view, rather than a lower position view, to yield the best esthetic results. ${ }^{33-36}$

Three intra-oral anatomic structures can be used efficiently to locate the midline, namely the nasopalatine papilla, the mid palatal suture, and the labial frenum with a less than one millimeter inaccuracy. Accordingly, determining the facial midline bisecting the nose, philtrum and tubercle of the upper lip can be an accurate process in most of the situations. ${ }^{37}$

Considering the patients' needs, retention and the sense of security were the main reasons for of appreciation of complete dentures. Recently patients are becoming more esthetically demanding, seeking near ideal teeth arrangements that are much better than any available pre-extraction record, and denture teeth with bleached shades. ${ }^{38-41}$

The currently available Digital Smile Design (DSD) computer software create a virtual wax-up, and provides insights into the perfect smile that most of the patients seek whether dentulous or edentulous. ${ }^{42,43}$

This study aimed to use one of these software packages to evaluate the already made complete dentures smile, and extract the criteria of a beautiful denture smile.

\section{MATERIALS AND METHODS}

This study aimed to use the features of the DSD software to evaluate the smile of complete dentures. Patients participated in this study were already having old complete dentures or just having their new dentures delivered. Sixty patients, 22 females and 38 males, attending the out-patient clinic at 
the college of dentistry, Qassim university in the kingdom of Saudi Arabia, ranged 40 to 70 years old, approved the consent, and were informed that the procedure was merely for research purposes and not part of their treatment. Institutional approval was also obtained before beginning of the study.

Two photos, in front centered view, were taken for each participant. In one photo the patients were asked to smile or to show their teeth, and in the second photo, the lips were retracted. Patients photos were then evaluated using a free trial of the Digital Smile System ( DSS available at: http:// www.digitalsmilesystem.com/en/features).

The DSD program was not used to design a new smile for the patients, however, its features were used to evaluate the dentures smile through objective analysis. Evaluation included centricity of the midline of the complete dentures using the

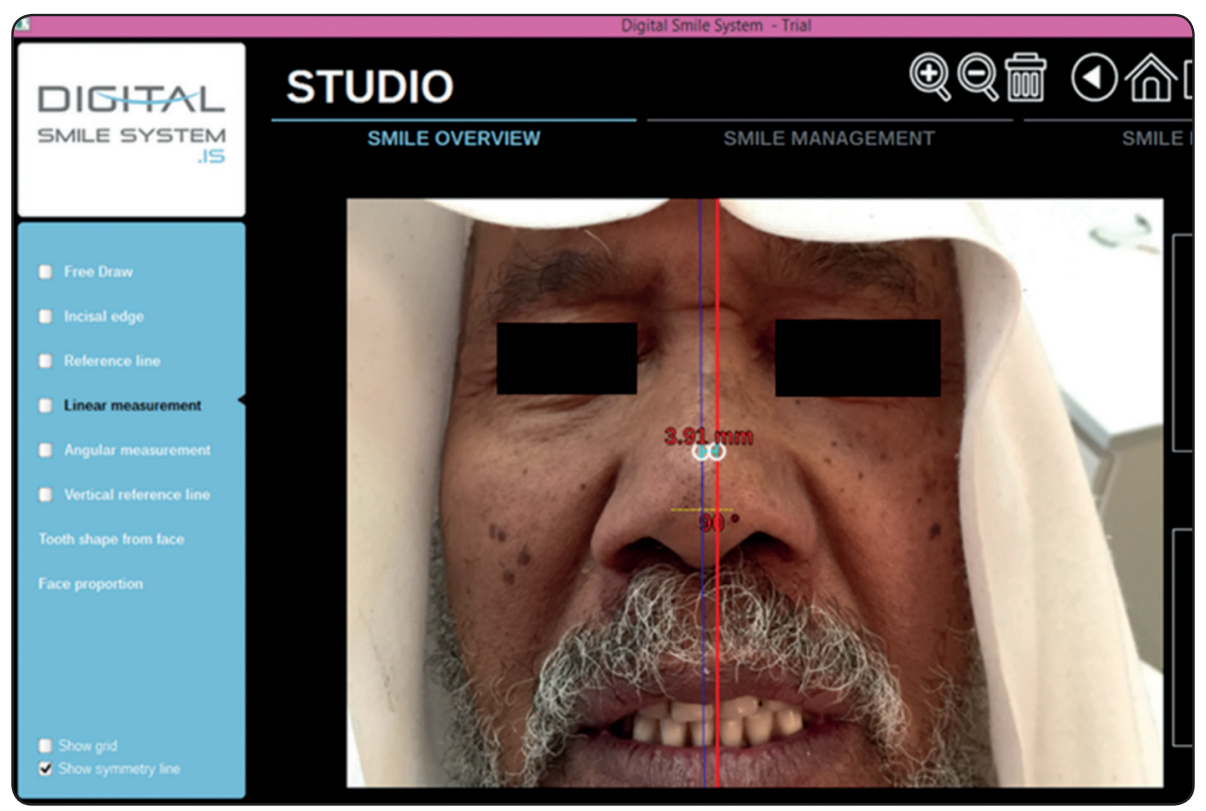

Fig. (1) The symmetry line feature of the DSS (red line) was used as the midline of the complete denture, and the reference line (blue line) was used as the midline of the patients face. In this case the denture midline was eccentric by $3.91 \mathrm{~mm}$. note that both lines were perfectly perpendicular making $90^{\circ}$ with the horizontal yellow line near the tip of the nose from below.

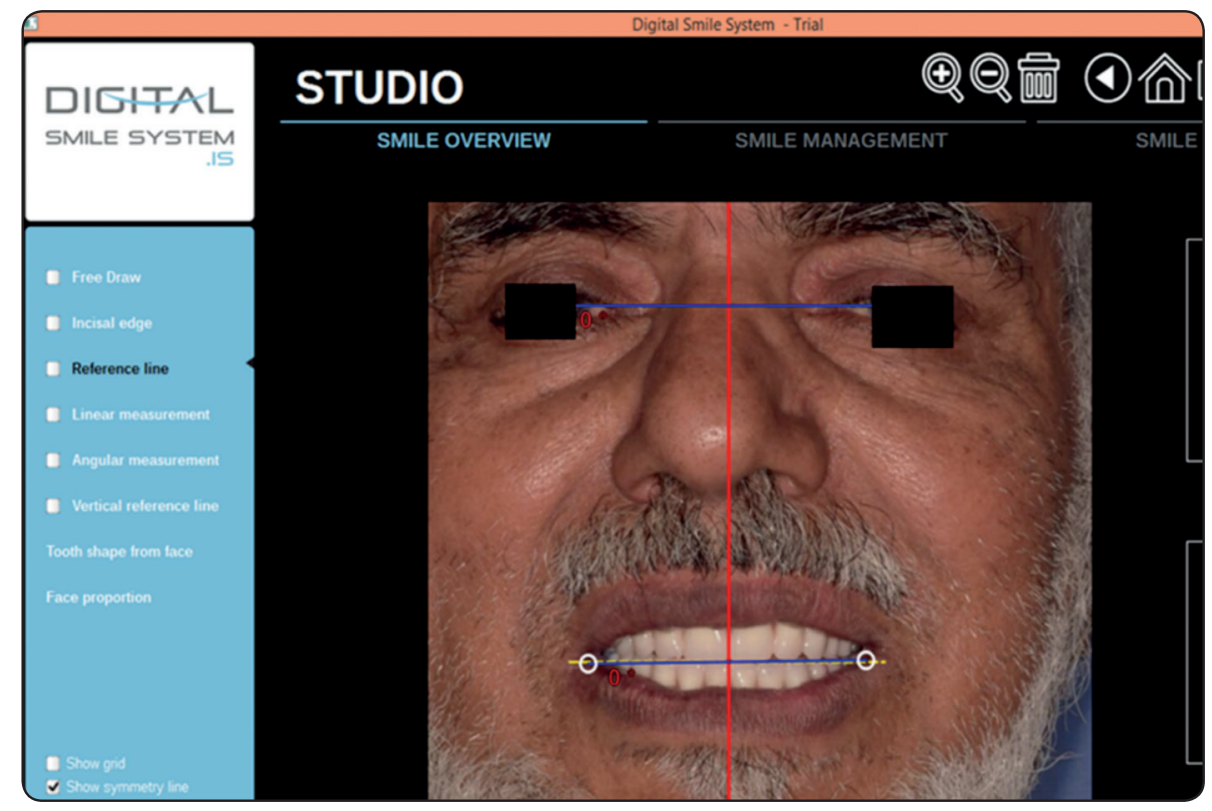

Fig. (2) Using the reference lines of the DSS to evaluate maxillary incisal plane parallelism to the IPL. In this case the maxillary incisal plane was parallel to the IPL, flat and not following the lower lip line, allowing some exposure of the mandibular incisor teeth when the lips were at rest position. 
symmetry line as seen in Figure 1, maxillary incisal plane parallelism to the inter pupillary line plane (IPL) using the reference lines as seen in Figure 2, and whether the incisal plane followed the lower lip line or not using the incisal plane line as seen in Figure 3. And finally, the linear measurements of the software were used to evaluate the equality of the combined width of the maxillary incisors and canines to the IAW as seen in Figure 4.
All the photos were evaluated by one examiner, the patients were also asked to comment on the form and shade of their dentures teeth, and all the data were displayed in the form of frequencies and percentages. The data were tabulated and analyzed using statistical package for social science (SPSS version 20 for windows). Comparisons between the study groups were carried out using Chi Square test at significance level $\mathrm{p}<.05$.

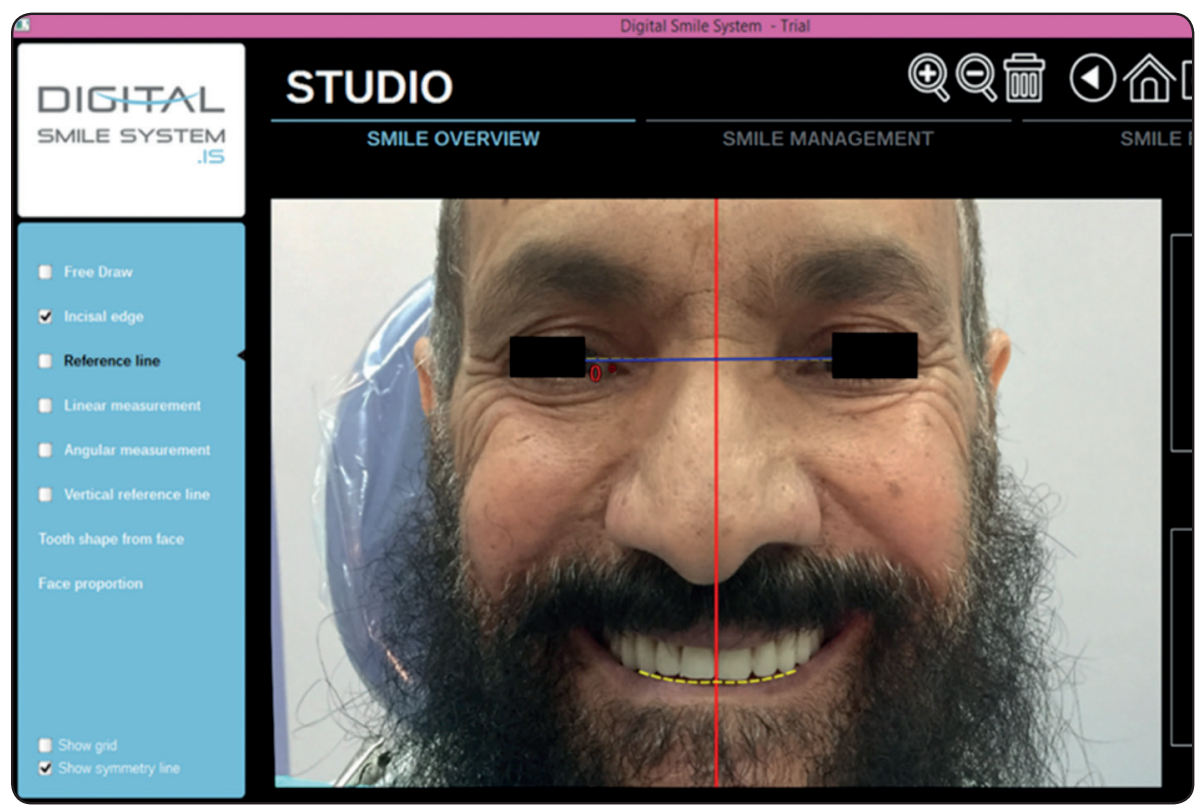

Fig. (3) Using the incisal edge feature of the DSS (yellow line) to determine if the maxillary incisal plane followed the lower lip line and if its planar average paralleled the IPL or not.

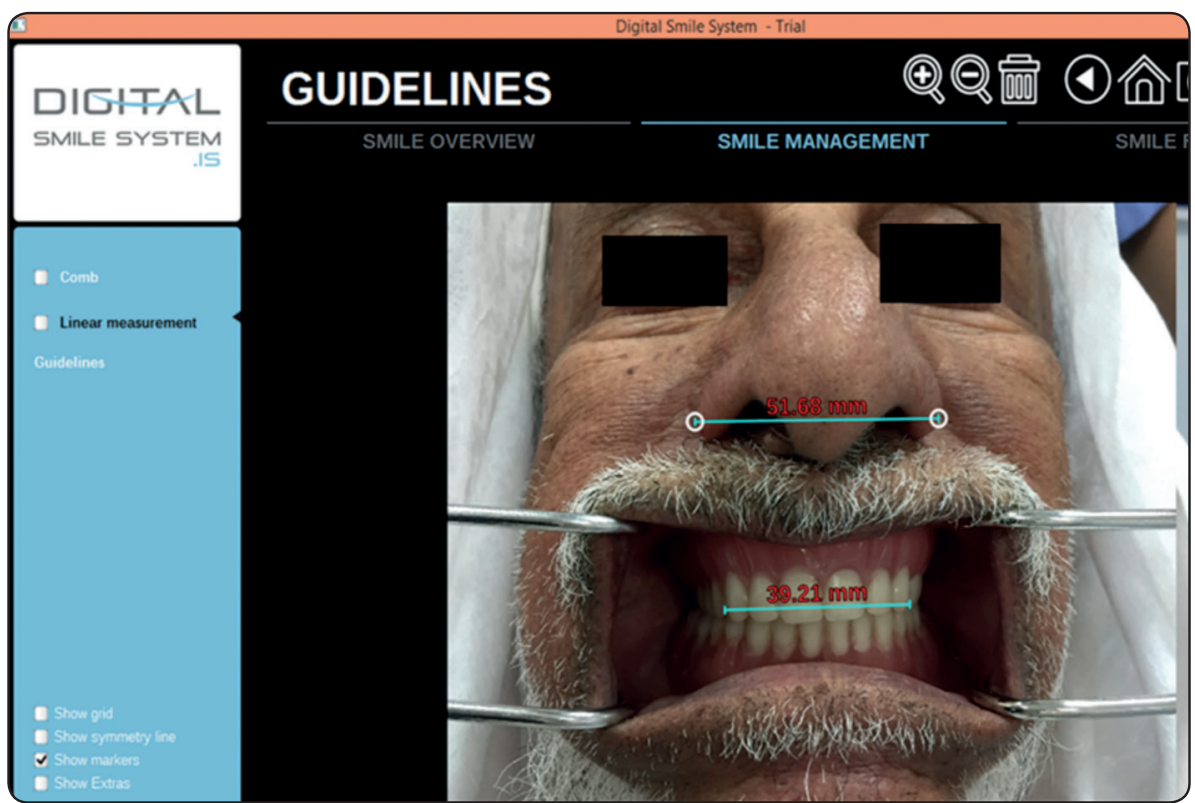

Fig. (4) Comparing the width of the 6 maxillary anterior teeth to the IAW of the nose using the linear measurements lines of the DSS. Numerical values were used to determine if the teeth were of the same width or smaller than the IAW. 


\section{RESULTS}

Table 1 presents the resulting data from the DSS software analysis of the 60 patients complete dentures smile, and it shows that the midlines of the maxillary dentures were coincident with the midline of the face and perpendicular to the maxillary incisal plane in 48 patients. Though being parallel to the IPL, the maxillary incisal plane was found to be flat and not following the lower lip line in 41 patients. The combined width of the maxillary denture anterior teeth was found to be the same as that of the IAW of the nose in 50 patients. Teeth forms were approved by 47 patients, these were square teeth for men, and ovoid for women. Finally, 42 of the patients needed a whiter shade, a higher value, even though the tooth shade of their dentures harmonized the color of their skin and hair.
There was a significant relationship between the centrally aligned midline of the dentures with the maxillary incisal plane $(\mathrm{p}=.001)$ whether following the lower lip line or not (Table 2), also, these midlines had a significant relationship with the width of the 6 maxillary anterior teeth $(\mathrm{p}=.001)$ when they equaled the IAW of the nose (Table 3 ).

The two genders did not have any significant difference in acceptance for the denture teeth form $(\mathrm{p}=.879)$ as displayed in Table 4 . However, there was a significant relationship ( $\mathrm{p}=.035)$ between gender and teeth shade, where the female patients needed a whiter shade more than the female patients as presented in Table 5.

TABLE (1) Analysis of the patients complete dentures smile.

\begin{tabular}{|l|l|l|}
\hline Comparison item & Description & $\mathrm{N}=60$ \\
\hline \multirow{4}{*}{ Midline } & Centrally aligned, perpendicular & 48 \\
\cline { 2 - 3 } & Eccentric & 12 \\
\hline \multirow{4}{*}{ Occlusal plane } & Parallel to the IPL, following the lower lip & 12 \\
\cline { 2 - 3 } & Parallel to the IPL, flat not following the lower lip & 41 \\
\cline { 2 - 3 } Width of the 6 maxillary anterior teeth & Not parallel to the IPL, flat not following the lower lip & 7 \\
\hline \multirow{3}{*}{ Tooth form } & Same width of the IAW & 50 \\
\cline { 2 - 3 } Tooth shade & Smaller than the IAW & 10 \\
\hline & Accepted by the patient. & 47 \\
\cline { 2 - 3 } & Not accepted by the patient. & 13 \\
\hline
\end{tabular}

N: number of patients.

TABLE (2) Relationship between midline and occlusal plane

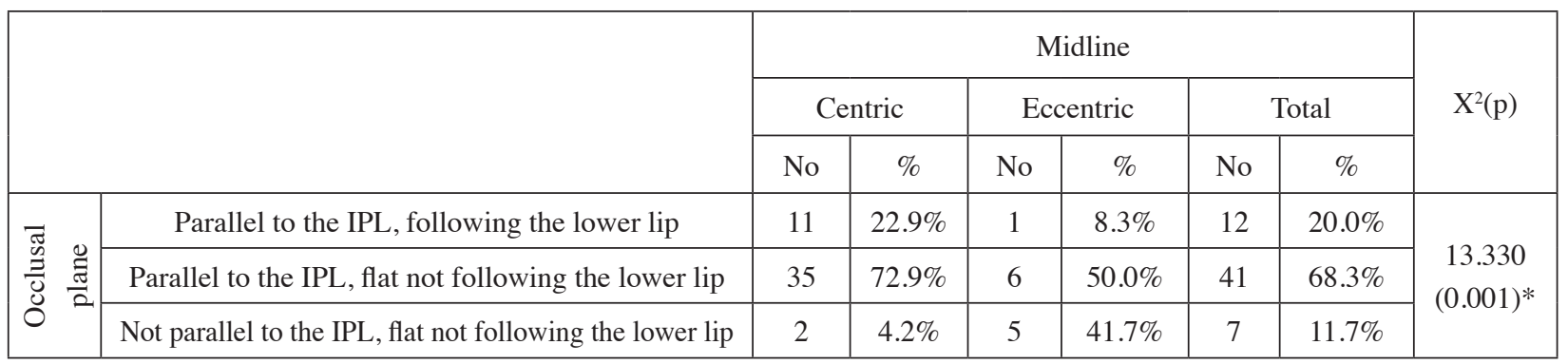


TABLE (3) Relationship between midline and width of maxillary anterior teeth width

\begin{tabular}{|c|c|c|c|c|c|c|c|c|}
\hline & & & & & dline & & & \\
\hline & & & tric & & ntric & & tal & $\mathrm{X}^{2}(\mathrm{p})$ \\
\hline & & No & $\%$ & No & $\%$ & No & $\%$ & \\
\hline Width of the 6 maxillary & Same as IAW & 45 & $93.8 \%$ & 5 & $41.7 \%$ & 50 & $83.3 \%$ & 18.750 \\
\hline anterio & Smaller IAW & 3 & $6.2 \%$ & 7 & $58.3 \%$ & 10 & $16.7 \%$ & $(0.001)^{*}$ \\
\hline
\end{tabular}

*P for chi Square test (X2), significant at $<.05$

TABLE (4) Relationship between gender and tooth form acceptance by patients

\begin{tabular}{|c|c|c|c|c|c|c|c|c|}
\hline & & \multicolumn{6}{|c|}{ Gender } & \multirow{3}{*}{$X^{2}(p)$} \\
\hline & & \multicolumn{2}{|c|}{ Male } & \multicolumn{2}{|c|}{ Female } & \multicolumn{2}{|c|}{ Total } & \\
\hline & & No & $\%$ & No & $\%$ & No & $\%$ & \\
\hline \multirow{2}{*}{$\begin{array}{l}\text { Tooth } \\
\text { form }\end{array}$} & Accepted by the patient. & 30 & $78.9 \%$ & 17 & $77.3 \%$ & 47 & $78.3 \%$ & \multirow[t]{2}{*}{$0.23(0.879)$} \\
\hline & Not accepted by the patient. & 8 & $21.1 \%$ & 5 & $22.7 \%$ & 13 & $21.7 \%$ & \\
\hline
\end{tabular}

*P for chi Square test (X2), significant at<.05

TABLE (5) Relationship between Gender and tooth shade acceptance by patients

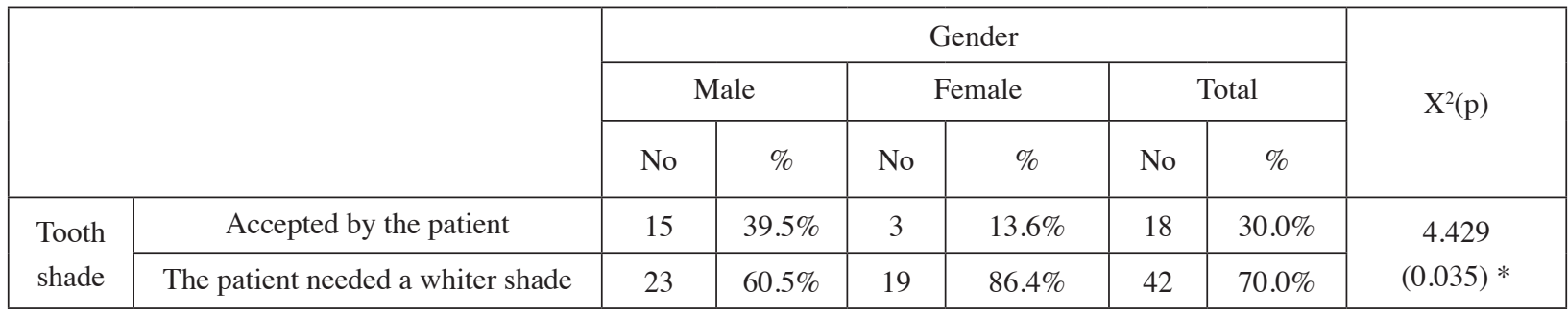

*P for chi Square test (X2), Significant at $<.05$

\section{DISCUSSION}

Complete dentures smile has usually been designed by the dentist, produced by the technician, and then the patients are given a chance to look at themselves through a mirror at the try-in stage. In contrast to the dentist who advises teeth arrangement that follows anatomical averages or any available pre-extraction record, and selection of tooth color that harmonizes with the hair and the skin, patients are becoming more esthetically demanding, seeking near ideal tooth arrangement and color.
Brewer $^{20}$ emphasized the impossibility of standard esthetic arrangement or composition of teeth that would be acceptable for all. Waliszewski ${ }^{40}$ has also referred to the same problem, and claimed that intraoral and extra oral landmarks of the completely edentulous patients have presented a low reliability for tooth selection or arrangement, and cannot be used to provide those patients with the same smile of dentate patients. However, several other studies ${ }^{15-22}$ have suggested that these biometric guides can be used to produce properly functioning dentures with a pleasant smile due to the restoration 
of the lips and cheeks to the positions when the natural teeth were present.

It also seemed that the dentists who used the extra oral landmarks, as esthetics guide lines, were able to successfully determine the midline of the face, and properly orient the occlusal plane anteriorly, this was approved by the significant relationship found between these two parameters in the results of this study, even though the anterior teeth did not follow the lower lip in most of the situations and allowed some exposure of the mandibular teeth. This came in agreement with the findings of Latta ${ }^{37}$, Kim et $\mathrm{al}^{36}$, and Brigante ${ }^{39}$ who confirmed that complete dentures maxillary incisors may not follow the lower lip line if this will increase the incisal guidance angle and make balanced occlusion more difficult to achieve. Also, Cade ${ }^{22}$ found it acceptable for complete dentures to show more of the mandibular incisors with the increase in age.

Another important finding of this study was the significant relationship of the midline of the face, when successfully allocated, to the combined width of the maxillary denture anterior teeth, when their width was equal to the IAW of the nose. This finding contradicted the work of Smith ${ }^{24}$ who could not relate the intercanine distance to the width of the nose in 80 male and female subjects, or Varjao et al ${ }^{26}$ who concluded that the nasal width method is not reliable and results in the selection of wider artificial teeth in any of their studied racial groups. However, in a completely edentulous patient situation, the use of the IAW will save the dentist a lot of the guess work, and will help easily determine the width of the maxillary denture anterior teeth as advocated by the findings of Hoffman et al ${ }^{25}$.

The dentures examined in this study had square teeth assigned for male patients and ovoid teeth forms in female patients' dentures, and neither of them showed any significant objection about these forms. This came in disagreement with Mavroskoufis and Ritchie ${ }^{33}$ who found no similarity between face- form and incisor tooth form. However, this finding comes in agreement with Shaweesh ${ }^{32}$ et al on the basis that certain tooth forms suite masculinity, having definite corners and prominent angles, such as square tooth forms, and other teeth forms suite femininity, being more rounded and having more gentle curves, such as the ovoid tooth forms.

On the other hand, there was a significant relationship between gender and teeth shade, where the female patients needed shades of higher values than the male patients. This came in agreement with Roumanas ${ }^{41}$ who stated that 'The mass media has tremendous influence on the esthetic tastes of our patients. Messages of health, power, and attractiveness are often linked to movie stars with prominent, white smiles'.

Finally, it is important to note that this study did not evaluate the denture base esthetics, and it is recommended that other studies in the future would consider the denture base color and topography. Also, it is recommended that prosthodontists can use the any available DSD software to create the denture smile after registration of jaw relations, or to evaluate the smile at the try-in stage, or to assess the smile of old prostheses before fabricating new dentures.

\section{CONCLUSIONS}

From the results of this study it can be concluded that proper allocation of the denture midline, determination of the IAW, orientation of the incisal plane as function and phonetics permit, and selection of the tooth form and shade that are suitable for the patient individuality, can yield a beautiful denture smile which may have the following criteria:

1. Accurately allocated dentures midlines that are coincident with the midline of the face and perpendicular to the maxillary incisal plane as found in most of the participants in this study $(\mathrm{p}=.001)$. 
2. Properly oriented maxillary incisal planes that are parallel to the IPL, and follows the lower lip line as much as incisal guidance allows.

3. Equal width of the maxillary 6 anterior teeth to the IAW of the nose, as found in this study $(\mathrm{p}=.001)$, which presented a fixed reference width, and together with centrally aligned midlines, symmetrical teeth arrangement become easily achieved.

4. Square teeth assigned to males and ovoid teeth assigned to female patients, in this study both sexes accepted these forms with no significant difference $(\mathrm{p}=.879)$.

5. Females required whiter teeth shades more than males $(\mathrm{p}=0.035)$

6. Since complete dentures smile was found to conform to the principles used in DSD, it is recommended to use the DSD software packages, which presented a simple and predictable method, for evaluation and production of highly esthetic complete dentures smile.

\section{REFERENCES}

1. Beder OE. Esthetics-an enigma. J Prosthet Dent 1971; 25: 588-591.

2. Hirsch B, Levin B, and Tiber N. Effects of patient involvement and esthetic preference on denture acceptance. J Prosthet Dent 1972; 28:127-132.

3. Lombardi RE. The principles of visual perception and their clinical application to denture esthetics. J Prosthet Dent 1973; 29:358-382.

4. Esposito SJ. Esthetics for denture patients. J Prosthet Dent 1980; 44:608-615.

5. Curtis TA, Shaw EL, and Curtis DA. The influence of removable prosthodontic procedures and concepts on the esthetics of complete dentures. J Prosthet Dent 1987; 57: 315-323.

6. Frush JP, Fisher RD. Introduction to dentogenic restorations. J Prosthet Dent 1955; 5: 586-95.

7. Frush JP, Fisher RD. How dentogenic restorations interpret the sex factor. J Prosthet Dent 1956; 6: 160-72.
8. Frush JP, Fisher RD. How dentogenics interprets the personality factor. J Prosthet Dent 1956; 6:441-9.

9. Frush JP, Fisher RD. The age factor in dentogenics. J Prosthet Dent 1957; 7:5-13.

10. Frush JP, Fisher RD. The dynesthetic interpretation of the dentogenic concept. J Prosthet Dent 1958; 8:558-81.

11. Frush JP, Fisher RD. Dentogenics: its practical application. J Prosthet Dent 1959; 9:914-21.

12. Dirksen LC. A natural esthetic buccal and labial anatomic form for complete dentures. J Prosthet Dent 1955; 5:368-375.

13. Kemnitzer DF. Esthetics and the denture base. J Prosthet Dent 1956; 6: 603-615.

14. Young HA. Denture esthetics. J Prosthet Dent 1956; 6: 748-755

15. Picard CF. Denture esthetics. J Prosthet Dent 1958; 8: 252259.

16. Martone AL. Effects of complete dentures on facial esthetics. J Prosthet Dent 1964; 14: 231-255.

17. Tautin FS. Denture esthetics is more than tooth selection. J Prosthet Dent 1978; 40:127-130.

18. Watt DM. Tooth positions on complete dentures. Journal of Dentistry. 1978; 6: 147-160.

19. Oh W, and Hansen C. Incisive papilla line as a guide to predict maxillary anterior tooth display. J Prosthet Dent 2009; 102:194-196.

20. Brewer A. Selection of denture teeth for esthetics and function. J Prosthet Dent 1969; 23: 368-373.

21. Vig RG, and Brundo GC. The kinetics of anterior tooth display. J Prosthet Dent 1978; 39:502-504.

22. Cade RE. The role of the mandibular anterior teeth in complete denture esthetics. J Prosthet Dent 1979; 42:368-370.

23. Varjão FM, and Nogueira SS. Correlating the curve distance between the distal of the canines to the combined width of the six anterior teeth when selecting denture teeth for different ethnic groups. J Prosthet Dent 2012;107: 400-404.

24. Smith BJ. The value of the nose width as an esthetic guide in Prosthodontics. J Prosthet Dent 1975; 34:562-573.

25. Hoffman W Jr, Bomberg TJ, and Hatch RA. Interalar width as a guide in denture tooth selection. J Prosthet Dent 1986; 55: 219-221. 
26. Varjao FM, Sualdini Nogueira SS. Nasal Width as a Guide for the Selection of Maxillary Complete Denture Anterior Teeth in Four Racial Groups. J Prosthodont 2006;15: 353-358.

27. Isa ZM, Tawfiq OF, Noor NM, Shamsudheen MI, and Rijal OM. Regression methods to investigate the relationship between facial measurements and widths of the maxillary anterior teeth. J Prosthet Dent 2010; 103:182-188.

28. Baker PS, Morris WJ, Lefebvre CA, Price GA, and Looney SW. Relationship of denture cast measurements to width of maxillary anterior teeth. J Prosthet Dent 2010;105: 44-50.

29. AL-Kaisy N, and Garib BT. Selecting maxillary anterior tooth width by measuring certain facial dimensions in the Kurdish population. J Prosthet Dent 2016; 115: 329-334.

30. Mavroskoufis F, and Ritchie GM. The face-form as a guide for the selection of maxillary central incisors. J Prosthet Dent 1980; 43:501-505.

31. Johnson PF. Racial norms: Esthetic and prosthodontic implications. J Prosthet Dent 1992; 67: 502-508.

32. Shaweesh AI, Al-Dwairi ZN, and Shamkhey HD. Studying the relationships between the outlines of the face, maxillary central incisor, and maxillary arch in Jordanian adults by using Fourier analysis J Prosthet Dent 2015; 113: 198-204.

33. Williams DR. Occlusal plane orientation in complete denture construction. Journal of Dentistry. 1982; 10: 31 $1-318$.

34. Mack MR. Perspective of facial esthetics in dental treatment planning. J Prosthet Dent 1996; 75: 169-176.
35. Kattadiyil MT, Goodacre CJ, Naylor WP, and Maveli. Esthetic smile preferences and the orientation of the maxillary occlusal plane. J Prosthet Dent 2012; 108: 354361.

36. Kim J, Topolski R, Dickinson D, and Ramos V. The influence of lip form on incisal display with lips in repose on the esthetic preferences of dentists and lay people. $\mathrm{J}$ Prosthet Dent 2017; 118: 413-421.

37. Latta GH Jr. The midline and its relation to anatomic landmarks in the edentulous patient. J Prosthet Dent 1988; 59: 681-683.

38. Brigante RF. Patient-assisted esthetics. J Prosthet Dent 1981; 46:14-20.

39. Waliszewski M. Restoring dentate appearance: A literature review for modern complete denture esthetics. J Prosthet Dent 2005; 93: 386-394.

40. Waliszewski M, Shor A, Brudvik J, and Raigrodski AJ. A Survey of Edentulous Patient Preference among Different Denture Esthetic Concepts. J Esthet Restor Dent. 2006; 18:352-369.

41. Roumanas ED. The Social Solution-Denture Esthetics, Phonetics, and Function. Journal of Prosthodontics 2009; 18:112-115.

42. Paul MMC, and Abraham ST. Golden proportion in denture esthetics. Health Sciences 2013;2:JS008.

43. Kamath R, Sharandha L, Ahanthem V. Smile Design: A Literature Review. Journal of Medical and Dental Science Research. 2016; 3 : 12-16. 